\title{
Arte y vida en Deleuze: formación estética y políticas de lo sensible
}

\author{
Art and life in Deleuze. Esthetic formation and policies of the sensible
}

\author{
Cynthia Farina* \\ Instituto Federal Sul-rio-grandense \\ Roselaine Machado Albernaz** \\ Instituto Federal Sul-rio-grandense
}

Resumo Este ensayo juega con un pequeño conjunto de ideas, tales como arte y formación estética, a partir del pensamiento de Gilles Deleuze. Para ello, se ocupa de nociones como estética y vida, en relación con la subjetividad, enfatizando sus procesos de formación. El texto presenta la noción de una política de lo sensible que nos sirve para indagar a nuestra formación estética, es decir, para indagar las políticas de fuerzas que componen a nuestra sensibilidad. Concluye e indica la importancia del campo del arte como disruptor de experiencias donde la razón no ordena lo sensible, donde el saber puede ser efecto de experiencias. Aproxima la producción de obras en el campo del arte y la producción de subjetividad en la vida, mediante el ejercicio de la creación.

palaVRas-ChaVe: Arte; Formación estética; Políticas de lo sensible.

Abstract This paper plays with a little set of ideas, such as art and esthetic formation, from Gilles Deleuze's thinking. Thus, it comprehends notions such as esthetic and life, in relation to subjectivity, emphasizing its processes of formation. The text presents the notion of a policy of the sensible which helps us to inquire our esthetic formation, that is, to wonder the policies of forces which are part of our sensibility. It concludes and indicates the importance of art field as a disruptor of experiences where reason does not order the sensible, where knowledge can be affected by experiences. It approximates the production of works in the field of art and production of subjectivity in life, through the exercise of creation.

KEYWORDS: Art; Esthetic formation; Policies of the sensible. 
Este ensayo pone sobre la mesa un conjunto de ideas como arte y formación estética, a partir del pensamiento de Gilles Deleuze. Para ello, se ocupa de nociones como estética y vida, en relación con la subjetividad, enfatizando sus procesos de formación. Se aborda la percepción como acción de lo sensible y la sensibilidad como efecto de la experiencia. Ver, oír y decir como ejercicios del hombre respecto a su misma capacidad sensible. Sin embargo, se destaca en el texto que tales ejercicios no se constituyen apenas como una práctica de la voluntad de ese hombre, sino, más bien, al revés: que ese hombre y los efectos de los que se hacen su visión y voz se producen en acontecimientos que les destituyen del poder de ver, oír y decir como lo hacían hasta entonces. Le interesa a Deleuze las formas frágiles del hombre, una cierta estética de la vulnerabilidad, a la que el arte contribuye.

En el año del 1978 Deleuze (2008) le dedica a Kant uno de sus cursos en la Universidad de Vincennes. Se interesa por mostrar el funcionamiento de su pensamiento, desea poner al descubierto sus engranajes. Desde ahí nos enseña como la sensibilidad de occidente ha sido educada a través de la dominancia de ese pensamiento, donde el orden sensible ha estado legislado por la razón. Para Kant, el terreno de lo sensible no produce ideas, no es capaz de generar conceptos, lo que le subordina, necesariamente, a la razón, como forma de acceder al plano ideal. El pensamiento estético deleuziano plantea problemas a las formas como lo sensible se ve representado por la razón. Ahí, el espacio de la experiencia se ve trazado como un espacio de resistencia a la percepción enjuiciadora, dibujando una teoría de lo sensible, un pensamiento estético de la experiencia. A esa teoría el presente texto da énfasis.

El pensamiento estético deleuziano que llega a dibujar una teoría del arte permite, aquí, que se presente la idea de una política de lo sensible como conjuntos de fuerzas actuantes sobre el espacio de la experiencia. Se dice que una política de este tipo constituye una cierta sensibilidad, maneras de ver, oír y decir la experiencia, maneras de darle voz y registro. En ese sentido, podemos hablar de unos procesos de formación estética donde lo que se sabe sobre la experiencia tiene que ver con las capacidades de lo sensible mismo, con las capacidades de vivir y dar expresión a lo vivido. De ahí la importancia de lo sensible en el pensamiento estético deleuziano, la importancia de la percepción con la que se da nuestra formación estética, que no esté ordenada por la razón y le permita al hombre una experiencia de formación como abertura a lo no sido, a lo no vivido y a lo no sabido. De ahí la importancia del arte como problematizadora de nuestra percepción y lógica, mediante las obras o hechos estéticos a los que somos capaces de dar vida colectivamente.

\section{Pensamiento estético deleuziano}

Para Deleuze, el arte tiene que ver con una forma de accionar el pensamiento. Una forma distinta de las demás, como la ciencia y la filosofía, propiamente estética (DELEUZE y GUATTARI, 1996). No se trata de una teoría de lo bello, una teoría del gusto o una filosofía del arte (ALMEIDA, 2008). Su obra no se propone como una teoría cualquiera sobre las artes, o una historia sobre las teorías estéticas, sino como un pensamiento sobre los modos de vida engendrado a partir del territorio del arte. Deleuze planteaba el arte como una forma específica de producir pensamiento con lo 
que afecta al terreno subjetivo. Se interesaba por las composiciones, agenciamientos y articulaciones que se producen en esa forma de pensar. Se trata de una reflexión sobre lo que el arte pone en juego y da que pensar sobre los modos de vida. El pensamiento para Deleuze tiene unos modos de funcionamiento particulares, pues no es fruto de la voluntad de un sujeto que piensa, sino de los acontecimientos que le fuerzan a pensar. Los acontecimientos presionan los modos de pensar, no respetan sus límites, e interfieren en la voluntad del sujeto. Los acontecimientos desencadenan una especie de violencia sobre el sujeto que le hace pensar. De ese modo, el pensamiento se produce por una violencia sufrida y no por una voluntad subjetiva. Y cuando esa violencia sobre el sujeto se encuentra en el territorio del arte, le hace pensar de una manera diferente, a través de procesos específicos.

La estética deleuziana se interesa por los conceptos a través de los cuales el arte genera obras que producen y alteran la vida misma. Para Deleuze, los conceptos estéticos desarrollados en el territorio del arte son maneras de vivir y generar la experiencia estética misma. Las obras de arte materializan los conceptos como el modo propio del pensar y del dar a pensar la experiencia de los sujetos. Esas obras (proposiciones, proyectos, objetos) encarnan los conceptos estéticos a través de los cuales el arte reflexiona acerca de la vida e interviene sobre ella. Las obras de arte materializan los conceptos estéticos que ponen en juego la vida y la realidad mediante modalidades específicas. Es decir, las obras son producidas por una forma específica de pensamiento ${ }^{1}$, propiamente estético, que trata de poner en juego las formas de vida del hombre. En ese sentido, Navarro (2001, p. 199) dice que: "la teoría estética deleuziana, como práctica de los conceptos del cine, de la novela, de la pintura, no se distingue ya de las preguntas propiamente filosóficas sobre la condición del hombre, de la vida o del pensamiento". Según Navarro, la estética deleuziana reflexiona sobre los modos de vida del hombre a partir de lo que le dan que pensar los conceptos estéticos.

Concepto estético y experiencia estética se encuentran en una existencia y pueden alterar sus formas de vida. Pueden alterar su percepción, el cuerpo a partir del cual escucha y pronuncia palabras que le dan contornos a la experiencia. Esas formas de vida tienen que ver concretamente con el pensamiento que les da soporte y el régimen sensible del que se constituyen (RANCIÉRE, 2002). Tienen que ver con un proceso de formación de lo existente que atraviesa su dimensión estética en tanto que productora de efectos audiovisuales. Tienen que ver con un proceso de formación estética. Es decir, con un proceso de formación de los modos de ver, oír y decir, de los modos de ubicarse en la realidad, que configuran a una subjetividad.

$\mathrm{El}$ arte es una forma de pensar por la cual el hombre se hace cargo de su condición subjetiva. Es una manera de dar visibilidad y dar voz a esa condición. El arte da a ver esa condición y sus conflictos, a través de conceptos que tratan de las formas de la vida y de las formas del hombre. De sus procesos de formación y transformación. Los conceptos que componen una obra problematizan los modos de vida del hombre, problematizan las formas en las que la vida se hace y los modos en que el hombre la experimenta. Los conceptos estéticos se engendran a través de imágenes, gestos, palabras y sonidos, a través de las formas bajo las cuales tornan visible y audible la experiencia humana. Por eso, las obras visten la fuerza de los acontecimientos que afectan las formas de vida y las formas de ser hombre. 


\section{Teoría de lo sensible}

El pensamiento estético deleuziano se ha constituido en relación a la estética kantiana, problematizando su estatuto de legitimidad y dominancia en Occidente. La empresa de ese pensamiento ha pretendido hacer visible los modos en que aquella había influenciado decisivamente las formas de vida modernas y contemporáneas. La estética kantiana se fundamenta en los principios de la jerarquía del juicio y de la crítica. Se fundamenta en la jerarquía de la conciencia sobre el mundo empírico, en el juicio de las ideas que legislan sobre lo sensible, y en la crítica que parte de la percepción pura de tiempo y espacio (KANT, 2001). La estética kantiana subordina la imaginación a la razón, en la medida en que lo sensible en Kant no se constituye como territorio propio del pensamiento. Es decir, no produce conceptos. De ahí la necesidad de la intervención de la razón en la imaginación, como forma de producir entendimiento sobre lo que le pasa al hombre en el terreno de lo sensible. Ahora bien, la estética kantiana se genera a partir de ideas puras, que existen a pesar de lo sensible, por ello lo sensible es concebido a través de categorías ideales. Dichas categorías tienen la prerrogativa de enjuiciar lo sensible, es decir, de ordenar lo sensible.

De ese modo, la estética kantiana puso en juego un juicio del gusto que ha prevalecido en el orden sensible de Occidente desde el siglo XVIII, legislando sobre la experiencia sensible a través de categorías ideales. El juicio estético kantiano ha categorizado, clasificado y jerarquizado lo sensible, dejando la experiencia sensible en manos de la razón. De ese modo, lo que ordena, clasifica y discrimina el juicio estético es lo que el hombre percibe en su experiencia. Es la percepción misma del hombre sobre su experiencia. Por eso, uno de los problemas que plantea el pensamiento estético deleuziano a la estética kantiana atañe a las formas por las que lo sensible se ve representado por la razón. Atañe a la misma posibilidad de que categorías ideales legislen sobre la percepción y la representación de lo sensible.

El pensamiento estético deleuziano supone un espacio de resistencia a esa idea de percepción que venía definida por la representación de lo sensible. Esa resistencia se da mediante la creación de un pensamiento estético de la experiencia, de la diferencia y de la percepción liberada de la representación. Se trata de una 'teoría de lo sensible' que Deleuze va a desarrollar acerca de la experiencia real. Se trata de producir conocimiento a partir de la experiencia real y no a partir de la representación de la experiencia ordenada. La teoría de lo sensible se interesa por las formas de la experiencia, por las condiciones que hacen que una experiencia sea real y no sólo una representación de lo 'posible'. Es decir, Deleuze va a desarrollar un modo de tratar la experiencia estética que la desmarca de los límites de la representación posible, para liberarla a la potencia de lo real.

Como se ha señalado, una de las críticas más importantes que hace Deleuze a la estética kantiana tiene que ver con el condicionamiento de la experiencia de lo sensible a una razón que la representa. En la estética kantiana, los límites de la experiencia estética están condicionados por un modo de percibir que representa la experiencia misma. La teoría de lo sensible argumenta en favor de que las formas de la experiencia no estén representadas y ordenadas por una percepción enjuiciadora, pues 
ese hecho las condiciona. De hecho, la experiencia de lo sublime en Kant se vincula a una teoría de la recepción del arte. Esa teoría de la recepción concierne a las representaciones por las que la razón interviene entre lo sensible y el sentido que le propone. Dichas representaciones sobre la experiencia definen las formas de la percepción que tienden a convertirse en formas fijas. Ahora bien, las formas de la percepción no se refieren sólo a la recepción por parte del sujeto de las obras producidas en el territorio del arte. Las formas de la percepción a las que se resiste la estética deleuziana, condicionan los modos sensibles que configuran las formas de la experiencia de los sujetos. La estética de la percepción no se limita a la 'recepción' de objetos de arte, sino que atañe a la vida de los sujetos y a los modos en que se constituyen los límites de su experiencia. De ahí que la conformación a priori de la experiencia mediante juicios de valor y criterios de jerarquía suponga una restricción de la potencia de la realidad. Lo que se ordena y dosifica en la representación de la experiencia es la potencia de vida, y lo que se recorta en las formas de la percepción son modelos de posibilidad. De ese modo, la estética deleuziana activa una manera de abordar la realidad y de dejarse interpelar por ella, una manera de producir discurso con la experiencia y no con sus representaciones. Y en ese abordar y dejarse interpelar por la realidad no se ignora lo que pueda alterar a la percepción misma, no se ignora lo discontinuo ni lo desconocido, como tampoco se tiene prisas en volverlo familiar.

\section{Políticas de lo sensible}

Ya se ha señalado que las maneras de pensar en el arte se formulan de un modo singular en ese campo, y que atañen a la realidad misma, configurada de una cierta manera. Pero, ¿en qué consiste el poder singular de los conceptos estéticos? Para Deleuze, el poder de tales conceptos concierne a su capacidad de hacer variar las formas de la experiencia sensible. Es decir, de hacer variar la percepción del sujeto, de alterar las formas de lo que se percibe como realidad. Esas variaciones no son necesariamente violentas, sino, más bien, micro-variaciones capaces de alterar, aunque ligeramente, un punto de vista. En una obra se articulan unos determinados conceptos estéticos que se tornan visibles, audibles o legibles, y que pueden provocar algún grado de variación en la percepción subjetiva. La singularidad de los conceptos articulados en una obra reside en su capacidad de poner en circulación, o de hacer circular de un modo nuevo, la realidad como potencia. Esa potencia tiene que ver con la fuerza contenida en los acontecimientos que impactan al terreno subjetivo. Esa potencia desestabilizadora es lo que contiene una obra. Deleuze se refiere a ello como la 'fuerza de novedad' de la que está hecha una obra, su capacidad de producir variaciones en el orden de lo sensible, las nuevas formas de experiencia que es capaz de crear.

Tales variaciones en el orden de lo sensible implican desestabilizaciones perceptivas y repercuten en los modos de ver la realidad. Repercuten en el régimen de fuerzas que configuran a esos modos, es decir, en las políticas de lo sensible (FARINA y HERNÁNDEZ, 2013). Una política de este tipo tiene que ver con la distribución, circulación y registro de fuerzas en un plano sensible, con las relaciones y dinámicas capaz de generar. Los hechos estéticos se inscriben en terrenos que poseen determinadas políticas, donde lo sensible se materializa y se expresa de determinadas formas a 
las que atañen una cierta formación estética. Interesa para el pensamiento deleuziano las formas como un concepto estético puede llegar a afectar los procesos de formación estética, y en este sentido, las formas de vida, es decir, los modos de afrontarla y constituir con ella un conjunto de nuevas referencias con y para la experiencia.

Podemos entender la formación como los procesos que conciernen a cada individuo y, a la vez, como los procesos que le ubican al individuo como fenómeno colectivo. En esos procesos se genera un conjunto de maneras no sólo de hacer, como de entender las cosas en la vida cotidiana - se genera la propia experiencia humana. Foucault (1996) nos enseña que esa experiencia tiene menos que ver con una acumulación de vivencias que con las maneras como les damos cauce, con las formas de cuidar de lo que nos pasa e improvisar con ello, de nombrar a esos hechos y nos ver en relación a ellos.

Si la noción de formación nos remite a una atención con los modos de hacer, la formación estética nos remite a una atención con los modos de ver y se expresar del hombre. La formación estética se da mediante la diversidad de imágenes, performances y discursos que la sostienen y que pueblan su cotidiano. Según Pardo (1991), tanto la acción de las imágenes (sean ellas visuales, metafóricas, musicales...) sobre las maneras de los sujetos de ver y vivir las cosas, como sus maneras de narrarlas, configuran su experiencia estética. De hecho, la experiencia estética se produce en medio a esas imágenes y discursos y por medio del ejercicio diario con ellos. La experiencia estética se constituye del conjunto de aprendizajes sensibles y conscientes de las que echamos mano, aunque sin darnos cuenta, para ver lo que nos pasa y responder a ello (SCHÉRER, 2012). Para Deleuze, un concepto que vive en un hecho estético puede llegar a provocar una experiencia y, con ello, un proceso de formación y transformación estética.

El pensamiento estético deleuziano no se interesa por interpretar la realidad materializada en el hecho estético, sino por tratar de cómo este hecho estético mueve la realidad. Lo que interesa en un hecho estético son sus formas de composición, sus modos de funcionamiento, las 'velocidades' que se arremolinan en su interior. Una idea que Deleuze y Guattari (1977, p. 68) exponían a propósito de Kafka: "es absolutamente vano censar un tema en un escritor, si no se pregunta cuál es su importancia exacta en una obra, es decir, exactamente cómo funciona (y no su 'sentido')". El modo de abordar un hecho estético implica su actividad performativa, lo que este hecho puede dar que pensar, lo que puede suscitar como reflexión y experiencia, como formación estética. Por eso, la teoría de lo sensible observa más las líneas de la composición de una práctica estética, las articulaciones que hace con otros campos de saber, que lo que parece 'decir' esta práctica. Este modo de preguntarse sobre una práctica estética no indaga sobre su sentido, sino que lo abre y desmonta, pues rompe los carteles indicativos de lectura o experimentación de esa práctica.

Las referencias que el sujeto tiene o que se le ofrecen para acercarse a una obra pueden funcionar como una especie de puerta de acceso. Sin embargo, la relación con esa obra no debe protegerse o refugiarse en esas referencias. Pues, para que de hecho algo le pueda pasar al sujeto en el encuentro con esa obra, lo que menos importa 
es su sentido y sus significados. De ese modo, no hay formulación de un método de interpretación de obras de arte en Deleuze: lo que importa es cómo acceder a las líneas de intensidad de las que se compone lo nuevo en una obra. Importa acceder a esa composición de fuerzas, a la política de lo sensible que expresa, porque es a través de ella que un hecho estético se compone con el poder de la realidad, porque es con esa fuerza que un hecho estético puede afectar la realidad.

Ahora bien, si el pensamiento estético deleuziano parte de una inversión de la estética kantiana (ya no se trata de ir de la representación a las cosas, sino de la experiencia con las cosas a la reflexión), tampoco tiene el arte como punto de llegada. El arte no es propiamente el objetivo de sus análisis. El pensamiento estético de Deleuze se presenta, más bien, como un territorio de crítica a los órdenes de los saberes y modos de ser dominantes de la sociedad y, a la vez, como territorio de creación de nuevos saberes y modos de ser. Los órdenes de los saberes dominantes intentan mantener inmóviles las fuerzas que desarreglan el sentido de la experiencia del sujeto. Intentan controlar el poder de afectación de lo real, para que no desordene el sentido construido de la experiencia. De ese modo, a través de los códigos de mantenimiento de dichos saberes, se inmovilizan tanto las formas de la experiencia como las formas del sujeto. Es decir, para la estética deleuziana el terreno del arte funciona como un campo de prácticas con las fuerzas que pueblan la realidad, en la medida que el arte puede hacer variar la percepción de la realidad y alterar la comprensión de la experiencia. Funciona como un campo de prácticas con las políticas de lo sensible que dan forma a lo real. De ahí que el arte pueda llegar a afectar a los órdenes de los saberes dominantes que componen el sentido que el hombre atribuye a la experiencia. Puede llegar a afectar las formas de la experiencia y sus procesos de formación.

$\mathrm{El}$ arte es un campo de experiencia con las fuerzas de la realidad que problematiza la percepción del hombre, presiona la identidad de la percepción y de lo que percibe. El arte promueve una experiencia de no reconocimiento de su propio sentido. En el campo del arte, los conceptos estéticos pueden promover la creación de nuevas percepciones fuera del sentido de las cosas tal como las conocemos (DELEUZE, 1994). El arte, como campo de producción de experiencias, no corrobora la 'lógica del sentido', y no deja confortables a los órdenes de saberes que controlan las líneas de vida. Por eso el arte interesa tanto a la filosofía de Deleuze, porque actúa sobre las formas de la percepción y del sentido del hombre, actúa sobre sus modos de vida. El arte tiene que ver, por tanto, con un territorio de extrañamiento de lo más íntimo del hombre y de sus propias formas. Y en ese aspecto, Deleuze (1998) es profundamente nietzscheano.

El pensamiento estético deleuziano se interesa por el arte como forma de crítica a los modos de vida dominantes de la sociedad. Se interesa por hacer variar los esquemas de sentido que condicionan o interrumpen los flujos vitales. Esa capacidad de crítica y de liberación de flujos vitales no tiene que entenderse vinculada al arte que se dice político o socialmente comprometido en sentido tradicional. La producción de arte que interesa al pensamiento deleuziano es la que se compone con los flujos y fuerzas vitales que actúan sobre los modos de ver y relacionarse con la existencia. Por eso dicen Deleuze y Guattari (2000, p. 191) que "el arte nunca es un fin, sólo es un 
instrumento para trazar líneas de vida". Líneas que se proyectan hacia el territorio del sinsentido, el territorio de lo sin-significado y lo no-subjetivo. El arte traza líneas de vida que escapan al sentido del arte, que escapan al sentido atribuido a la realidad. Esas líneas arrastran consigo el sentido hacia una zona de indeterminación, donde es difícil identificar el significado de la realidad que se percibe (DELEUZE, 2002). En esa zona no reconocible, las representaciones y las interpretaciones sobre la realidad tienen poco sentido, pues la percepción no se identifica con su propio sistema perceptivo. La apuesta del pensamiento estético deleuziano por la producción de novedad en la creación atañe a nuevas formas de existencia, en la medida que el arte se compone de la potencia de la realidad.

\section{Referências}

ALMEIDA, A. et al. A experiência e o juízo estéticos. In: A arte de pensar. Lisboa: Didáctica, 2008. Disponível em: <http://aartedepensar.com/acetatos/capitulo12.pdf >.

DELEUZE, G. Francis Bacon. Lógica de la sensación. Madrid: Arena, 2002.

. Kant y el tiempo. Buenos Aires: Cactus, 2008.

. Lógica del sentido. Barcelona: Paidós, 1994.

Nietzsche e a filosofia. Porto: Rés, 1998.

DELEUZE, G.; GUATTARI, F. Kafka: por una literatura menor. Rio de Janeiro: Imago, 1977. O que é a Filosofia? Rio de Janeiro: ed. 34, 1996.

FARINA, C.; HERNÁNDEZ, E. (Orgs.). Cosméticas y políticas del cuerpo. Educación de lo sensible. Cali: Alfagraphics, 2013.

FOUCAULT, M. Hermenéutica del sujeto. La Plata: Altamira, 1996.

KANT, I. Crítica del juicio. Madrid: Colección Austral, 2001.

NAVARRO, A. Introducción al pensamiento estético de Deleuze. Valencia: Tirant lo Blanch, 2001.

PARDO, J. L. Sobre los espacios: pintar, escribir, pensar. Barcelona: Serbal, 1991.

RANCIÉRE, J. La división de lo sensible. Estética y política. Salamanca: Centro de Arte de Salamanca, 2002.

SCHÉRER, R. Miradas sobre Deleuze. Buenos Aires: Cactus, 2012.

Notas

${ }^{1}$ La referencia a un pensamiento estético deleuziano, no deja de lado la importante contribución de Guattari para este pensamiento. Sin embargo, se destaca aquí intereses filosóficos más específicamente deleuzianos, que se refieren a la forma en el territorio del arte.

* Professora doutora do Instituto Federal Sul-rio-grandense, Pelotas, Rio Grande do Sul, Brasil.

** Professora doutora do Instituto Federal Sul-rio-grandense, Pelotas, Rio Grande do Sul, Brasil. 


\section{Correspondência}

Cynthia Farina - Instituto Federal Sul-rio-grandense, Programa de Pós-graduação em Educação. Praça 20 de Setembro, 455 - COLINC, Centro. CEP: 96015360. Pelotas, Rio Grande do Sul, Brasil.

E-mail: cynthiafarina@pelotas.ifsul.edu.br - rosealbernaz@gmail.com

Recebido em 22 de junho de 2015

Aprovado em 14 de dezembro de 2016 
